\title{
Masking Level Difference: Performance of School Children Aged 7-12 Years
}

\author{
Nádia Giulian de Carvalho', Maria Isabel Ramos do Amaral ${ }^{2}$, \\ Vinicius Zuffo de Barros ${ }^{3}$, and Maria Francisca Colella dos Santos ${ }^{1,2}$ \\ ${ }^{1}$ Child and Adolescent Health, the Pediatric Research Center, São Paulo, Brazil \\ ${ }^{2}$ Department of Human Development and Rehabilitation, School of Medical Sciences, the University of Campinas, São Paulo, Brazil \\ ${ }^{3}$ Technical Training, São Paulo Research Foundation, São Paulo, Brazil
}

\author{
Received December 29, 2019 \\ Revised March 31, 2020 \\ Accepted September 21, 2020 \\ Address for correspondence \\ Nádia Giulian de Carvalho, MSc \\ Child and Adolescent Health, \\ the Pediatric Research Center, \\ Tessália Vieira de Carmargo, \\ 126 University City Zeferino Vaz, \\ Campinas, São Paulo 13083-894, \\ Brazil \\ Tel $+55-19-3521-8800$ \\ Fax $+55-19-3521-8970$ \\ E-mail nadiagiulian@gmail.com
}

\begin{abstract}
Background and Objectives: In masking level difference (MLD), the masked detection threshold for a signal is determined as a function of the relative interaural differences between the signal and the masker. Study 1 analyzed the results of school-aged children with good school performance in the MLD test, and study 2 compared their results with those of a group of children with poor academic performance. Subjects and Methods: Study 1 was conducted with 47 school-aged children with good academic performance (Gl) and study 2 was carried out with 32 school-aged children with poor academic performance (GII). The inclusion criteria adopted for both studies were hearing thresholds within normal limits in basic audiological evaluation. Study 1 also considered normal performance in the central auditory processing test battery and absence of auditory complaints and/or of attention, language or speech issues. The MLD test was administered with a pure pulsatile tone of $500 \mathrm{~Hz}$, in a binaural mode and intensity of $50 \mathrm{dBSL}$, using a CD player and audiometer. Results: In study 1, no significant correlation was observed, considering the influence of the variables age and sex in relation to the results obtained in homophase (SoNo), antiphase ( $\mathrm{S} \pi \mathrm{No}$ ) and MLD threshold conditions. The final mean MLD threshold was $13.66 \mathrm{~dB}$. In study 2, the variables did not influence the test performance either. There was a significant difference between test results in $\mathrm{S} \pi$ No conditions of the two groups, while no differences were found both in SoNo conditions and the final result of MLD. Conclusions: In study 1, the cut-off criterion of school-aged children in the MLD test was $9.3 \mathrm{~dB}$. The variables (sex and age) did not interfere with the MLD results. In study 2, school performance did not differ in the MLD results. Gll group showed inferior results than Gl group, only in $\mathrm{S} \pi \mathrm{No}$ condition.

J Audiol Otol 2021;25(2):65-71
\end{abstract}

\section{Introduction}

Hearing and understanding sound information with quality involves hearing structures related to specific auditory skills such as sound localization and lateralization, auditory discrimination, recognition of temporal aspects, and performance with competitive and degraded acoustic signals [1]. The behavioral central auditory processing (CAP) test battery may contribute to a differential diagnosis in the central auditory nervous

This is an Open Access article distributed under the terms of the Creative Commons Attribution Non-Commercial License (https://creativecommons.org/licenses/by-nc/4.0/) which permits unrestricted non-commercial use, distribution, and reproduction in any medium, provided the original work is properly cited. system (CANS) and to assess specific listening skills that are important for learning [2]. The American Speech-Language Hearing Association (ASHA) [1] recommends the administration of a test battery with at least one test evaluating each mechanism/skill, including binaural interaction.

Binaural interaction depends on the ability of the auditory system to process interaural differences of time, phase and sound intensity [3]. Binaural hearing has advantages compared to hearing with only one ear. Sound source localization depends on the analysis and comparison of the stimuli reaching the right and left ears. In addition, binaural hearing improves auditory sensitivity, that is, more accurate localization of auditory signals, and oral comprehension in noisy environ- 
ments when sound sources are spatially separated $[4,5]$.

The mechanism of binaural interaction starts in the subcortical area of the CANS, more specifically in the superior olivary complex and a region near the nucleus of the lateral lemniscal and the inferior colliculus $[6,7]$. The auditory cortex may also be involved, distributing information processed along the auditory pathway related to the acoustic cues, directing such information to proper perceptual and motor spatial processing areas [8].

Auditory skills refer to the auditory system and are bottomup factors related to the representation of acoustic signals. However, the act of hearing does not merely imply detection of an acoustic stimulus, since auditory skills depend on several neurophysiological and cognitive mechanisms. Moreover, top-down processes are necessary — even the simplest auditory event is influenced by higher-level cognitive factors such as memory, attention and learning [9].

Binaural interaction is also linked to selective attention, but some studies suggest that attention and cognitive skills have little influence on this mechanism [4]. At school, students are required to pay attention to what the teacher says, ignoring other stimuli that may affect listening and, consequently, learning [10]. School difficulties/poor academic performance are global and comprehensive terms commonly used to designate low academic achievement of students that is incompatible with their cognitive skills [11].

These issues require multidisciplinary assessment, considering that Central Auditory Processing Disorder (CAPD) is best viewed as a "deficit in neural processing of auditory stimuli that may coexist with, but is not the result of, dysfunction in other modalities." [1] This underscores the need for comprehensive assessment and diagnostic procedures to fully explore the nature of the difficulties shown by each individual [1].

The psychoacoustic phenomenon defined as masking release shows improved detection or recognition of a signal in mono or binaural conditions in the presence of competitive bilateral noise. This improvement is a result of the auditory system being triggered by a subtle binaural event and of differences in amplitude levels between simultaneous or masked signals $[12,13]$. Masking release can be clinically evaluated, and one of the procedures to evaluate binaural interaction is a supraliminal test named masking level difference (MLD).

In MLD, the masked detection threshold for a signal is determined as a function of the relative interaural differences between the signal and the masker [3]. The MLD test is typically a threshold measure, usually expressed in decibels as the difference between a homophasic and an antiphasic condition, in which the signal or the noise is out of phase. MLDs seem to be more sensitive and reduced in cases of disease or lesions in the brainstem [14]. This test is consolidated in the literature and in international clinical practice. It can be performed using different parameters of administration - for example, noise and pure tone in the same phase (SoNo), noise in reversed phase in one ear and pure tone in phase in both ears $(\mathrm{SoN} \pi)$, or pure tone in reversed phase in one ear and noise in phase in both ears $(\mathrm{S} \pi \mathrm{No})[12]$. Besides different administration protocols, some versions are available with recorded materials or coupled to audiometers $[5,10,15,16]$.

Despite the importance of the MLD test in the evaluation battery and its growing clinical use, few studies have been conducted with Brazilian adult [17] and pediatric populations $[10,18]$. Previous studies have shown various results regarding the MLD scores of school-aged children throughout many countries $[5,10]$. No normality standard for Brazilian schoolaged children has been defined yet. Therefore, this research conducted two studies. Study 1 analyzed the results of schoolaged children with good school performance in the MLD test. Study 2 analyzed the results of school-aged children with poor school performance in the same test and then compared the results of both groups.

\section{Subjects and Methods}

\section{Design, site and ethical aspects of studies}

Both are prospective and descriptive cross-sectional studies conducted with a convenience sample in partnership with a public school of Dona Castorina Cavalheiro (municipal education system). Authorized by the school board, the researcher invited the students to participate in the analysis - an invitation letter was initially sent to the parents to explain the proposal. The informed consent form was then signed by all parents and/or guardians who agreed to participate, as well as by the children. The research was also approved by the Research Ethics Committee of University of Campinas (No. 2294609).

\section{Study 1}

Study 1 analyzed the results in the MLD test of 47 schoolaged children with good school performance, with a mean age of $9.29 \pm 1.08$ years and 26 females. Sex and age were considered as variables.

The inclusion criteria adopted were absence of auditory complaints and/or of attention, language or speech issues. Teachers and parents reported on students' performance in the classroom (behavior and school record). To evaluate this information, a questionnaire with 10 items was answered by the teachers of each class. The document addressed topics such as student participation in the classroom, good school performance, focus on activities, behavior at school, interaction with other chil- 
dren and adults, evidence of respiratory and/or hearing disorders, articulation (phonetic) disorder, and difficulty in recognizing phonemes in writing and reading comprehension. In addition to these questions, parents answered whether the child had reading and writing difficulties, attended support classes and had failed any grade.

Moreover, normal hearing was analyzed by auditory tests: auditory thresholds $\leq 15 \mathrm{~dB}$ in frequencies from 0.25 to $8 \mathrm{kHz}$ [19], speech recognition index greater than 88\% [20], type A tympanometric curve with ipsilateral and contralateral acoustic reflexes [21] and normal performance in the CAP test battery validated for Brazilian Portuguese [22], considering the ASHA criterion of a minimum of two altered tests to detect CAPD.

\section{Study 2}

Study 2 analyzed the results in the MLD test of 32 children with school difficulties/poor academic performance, with a mean age of $8.63 \pm 0.92$ years and 17 females, and then compared the results of this group, called GII, with the results of the group of children with good school performance in study 1 , called GI. Sex and age were also considered as variables. The inclusion criteria adopted for GII was children with poor academic performance reported by teachers and parents, considering classroom performance and school record and the same questionnaire answered by teachers and parents in study 1 . Other inclusion criteria used in this study were normal hearing (tested by peripheral hearing assessment [19-21]) and understanding instructions in the administered tests. However, normality in the CAP diagnostic battery was not considered as an inclusion criterion.

\section{Procedures for study 1 and 2}

Data were collected in the following order: 1) Signing of the Informed Consent Form (ICF) and anamnesis with parents and/or guardians, 2) Otoscopy, 3) Peripheral hearing assessment, 4) MLD, 5) Dichotic digits test (DDT) in the stage of binaural integration, with a list of 80 digits, two presented in each ear simultaneously [22], 6) Pediatric speech intelligibility (PSI) test or synthetic sentence identification (SSI) [22], with ipsilateral competing message at $-15 \mathrm{~dB}$ signal/noise ratio, 7) Random interval detection test (RGDT) for detecting the temporal acuity threshold [23], 8) Noise speech test (NST) which consists of 25 monosyllabic words with white noise, presented monoaurally, and 9) Frequency pattern test (FPT), presented for the labeling task, using the Auditec ${ }^{\circledR}$ (Auditec, Inc., St. Louis, MO, USA) [24] version for children aged 7 and 8 , and the Musiek version (available from https://auditec.com/price/; Auditec, Inc., St. Louis, MO, USA) for chil- dren over 9 years old [25].

The descriptive analysis [mean and standard deviation (SD)] in the CAP battery of school-aged children with good (GI) and poor (GII) academic performance is shown in Table 1 . It is noteworthy that in GII, $46 \%$ were classified with CAPD, considering two altered tests.

Before the administration of the auditory processing tests, a 10-minute break was taken for the child to snack. The following equipment was used in the test: otoscope, AC40 audiometer (Interacoustics, Middelfart, Denmark) and AT235h immittance meter (Interacoustics, Middelfart, Denmark), and administered in a soundproof cabin.

The MLD test administered was the Auditec of Saint Louis version (Auditec, Inc., St. Louis, MO, USA), with $500 \mathrm{~Hz}$ pure pulsating tone. A binaural mode of $50 \mathrm{dBSL}$ (sensation level) was used, considering the mean of the pure tone thresholds at $500 \mathrm{~Hz}, 1$ and $2 \mathrm{kHz}$ (a CD player was connected to the audiometer developed by Richard Wilson [26]). Each child received the following instruction: "You will hear the sound of rain (noise) with a whistle, like a busy telephone. At another moment, only rain (noise) will be heard. Raise your hand when

Table 1. Performance in the central auditory processing battery of school children aged $7-8$ and over 9 years old

\begin{tabular}{lcc}
\hline & GI & GII \\
\hline CAPD tests at 7-8 years old & $\mathrm{n}=25$ & $\mathrm{n}=26$ \\
DDT right ear (\%) & $89.62 \pm 9.23$ & $86.67 \pm 6.83$ \\
DDT left ear (\%) & $92.50 \pm 7.07$ & $87.73 \pm 8.76$ \\
PSI right ear (\%) & $86.00 \pm 10.80$ & $81.54 \pm 16.17$ \\
PSI left ear (\%) & $82.40 \pm 10.52$ & $78.08 \pm 15.75$ \\
RGDT (ms) & $5.37 \pm 2.77$ & $5.25 \pm 3.40$ \\
NST right ear (\%) & $88.96 \pm 4.21$ & $88.23 \pm 7.07$ \\
NST left ear (\%) & $90.24 \pm 4.91$ & $88.23 \pm 8.66$ \\
FPT right ear (\%) & $87.50 \pm 17.12$ & $76.67 \pm 15.06$ \\
FPT left ear (\%) & $80.00 \pm 18.26$ & $70.00 \pm 40.82$ \\
CAPD tests at >9 years old & $\mathrm{n}=22$ & $\mathrm{n}=6$ \\
DDT right ear (\%) & $98.13 \pm 2.50$ & $91.67 \pm 2.89$ \\
DDT left ear (\%) & $97.35 \pm 2.57$ & $87.50 \pm 3.54$ \\
SSI right ear (\%) & $70.45 \pm 12.90$ & $58.33 \pm 21.37$ \\
SSI left ear (\%) & $68.18 \pm 13.68$ & $55.00 \pm 28.11$ \\
RGDT (ms) & $5.50 \pm 4.12$ & $3.50 \pm 2.12$ \\
NST right ear (\%) & $94.91 \pm 2.81$ & $94.00 \pm 4.90$ \\
NST left ear (\%) & $94.91 \pm 3.31$ & $94.00 \pm 4.20$ \\
FPT right ear (\%) & $58.89 \pm 17.64$ & $30.00 \pm 8.16$ \\
FPT left ear (\%) & $50.00 \pm 31.17$ & $20.00 \pm 10.00$ \\
\hline Vales are presented as mean $\pm 5 t a n d a r d ~$ & \\
\hline
\end{tabular}

Values are presented as mean \pm standard deviation. Gl: schoolaged children with good academic performance, Gll: schoolaged children with poor academic performance, CAPD: central auditory processing disorder, DDT: dichotic digits test, PSI: pediatric speech intelligibility, RGDT: random interval detection test, NST: noise speech test, FPT: frequency pattern test, SSI: synthetic sentence identification 
you hear the whistle. If you only hear the rain (noise), do not raise your hand." Thirty-three segments of narrowband noise were used in three different conditions: SoNo (homophase signal and noise in both ears), $\mathrm{S} \pi \mathrm{No}$ (antiphase signal in one ear and homophase noise in both ears), and NT (no tone, which means only noise with no signal). All correct answers from each phase were counted and converted into a new value by means of a conversion table for threshold calculation in $\mathrm{dB}$, using the test response table. Then, the value of out-phase stimuli ( $\mathrm{S} \pi \mathrm{No}$ ) was subtracted from the in-phase value (SoNo), resulting in the MLD threshold value.

\section{Statistical analysis}

SPSS V20 (IBM Corp., Armonk, NY, USA), Minitab 16 (LLC, State College, PA, USA) and Excel Office 2010 (Microsoft, Redmond, WA, USA) were used for statistical analysis. Normality of the main outcome quantitative variables was tested by the Kolmogorov-Smirnov (KS) test and nonparametric tests were also used. To describe the sample profile according to the study variables, we developed frequency tables of the categorical variables, with absolute frequency (n) and percentage (\%) values, and descriptive statistics of the numerical variables with mean, SD and median values. The Chisquare test was used to compare the categorical variables and the Mann-Whitney U test was used for numerical variables. The relationship between numerical variables was analyzed using Spearman's correlation coefficient. $p<0.05$ was considered as statistically significant.

\section{Results}

\section{Study 1}

In school children with good school performance (GI), the variable age had a negative correlation with the SoNo threshold ( $p=0.036)$, although it was a weak correlation coefficient $(-0.307)$, with no clinical relevance. No significant correlation was observed in the $\mathrm{S} \pi$ No $(p=0.445)$ and $\operatorname{MLD}(p=0.105)$ threshold conditions. The variable sex did not influence the performance of GI in any condition of the MLD test (Table 2). The cut-off criterion of school-aged children with good academic performance in the MLD test was $9.3 \mathrm{~dB}$, considering the mean of the MLD threshold subtracted from two SDs (Table 3).

\section{Study 2}

Tables 4 and 5 show the characterization and comparison of the two groups. The groups were considered heterogeneous in terms of age (Table 4) and homogeneous in terms of sex (Table 5).
In school-aged children with poor academic performance (GII), no significant correlation was observed in the variable age in relation to the results obtained in the SoNo $(p=0.425)$, $\mathrm{S} \pi$ No $(p=0.621)$ and MLD $(p=0.846)$ threshold conditions. The variable sex did not influence the performance of GII in any condition of the MLD test (Table 2).

Table 2. Comparison of the variable sex in $\mathrm{GI}$ and $\mathrm{GII}$ in relation to the results obtained in the homophase (SoNo), antiphase ( $\mathrm{S} \pi \mathrm{No}$ ) and MLD threshold conditions

\begin{tabular}{lccccc}
\hline Variable & $\mathrm{n}$ & Condition & Mean & SD & p-value \\
\hline GI-F & 26 & SoNo & -12.77 & 6.93 & 0.699 \\
& & S $\pi$ No & -27.62 & 2.33 & 0.824 \\
& & MLD & 13.62 & 2.19 & 0.955 \\
GI-M & 21 & SoNo & -12.67 & 6.14 & \\
& & S $\pi$ No & -27.52 & 2.27 & \\
& & MLD & 13.71 & 2.22 & \\
GII-F & 17 & SoNo & -13.06 & 4.64 & 0.923 \\
& & S $\pi$ No & -25.06 & 4.42 & 0.623 \\
& & MLD & 13.18 & 4.59 & 0.728 \\
GII-M & 15 & SoNo & -12.80 & 3.00 & \\
& & S $\pi$ No & -26.13 & 2.77 & \\
& & MLD & 13.33 & 2.69 &
\end{tabular}

Data were analyzed using Mann-Whitney test. SD: standard deviation, Gl: school-aged children with good academic performance, Gll: school-aged children with poor academic performance, F: female, M: male, MLD: masking level difference

Table 3. Comparison between the performance of school-aged children (GI and GII) in relation to the results obtained in the homophase (SoNo), antiphase ( $\mathrm{S} \pi \mathrm{No}$ ) and MLD threshold conditions

\begin{tabular}{ccccc}
\hline Group & Mean & Median & SD & p-value \\
\hline S $\pi$ No & & & & 0.007 \\
GI & -27.57 & -28.0 & 2.28 & \\
GII & -25.56 & -26.0 & 3.72 & \\
SoNo & & & & 0.158 \\
GI & -12.72 & -14.0 & 6.52 & \\
GII & -12.94 & -14.0 & 3.90 & \\
MLD & & & & 0.691 \\
GI & 13.66 & 14.0 & 2.18 & \\
GII & 13.25 & 13.0 & 3.76 & \\
\hline
\end{tabular}

SD: standard deviation, Gl: school-aged children with good academic performance, GII: school-aged children with poor academic performance, MLD: masking level difference

Table 4. Characterization of sample age and comparison between $\mathrm{GI}$ and GII

\begin{tabular}{lccc}
\hline \multicolumn{1}{c}{ Age } & $\mathrm{GI}(\mathrm{n}=47)$ & $\mathrm{GII}(\mathrm{n}=32)$ & $\mathrm{p}$-value \\
\hline Mean & 9.29 & 8.63 & 0.002 \\
Median & 8.83 & 8.33 & \\
Standard deviation & 1.02 & 0.92 & \\
\hline
\end{tabular}

Data were analyzed using Mann-Whitney test. Gl: school-aged children with good academic performance, Gll: school-aged children with poor academic performance 
Table 5. Characterization of sample sex and comparison between $\mathrm{Gl}$ and $\mathrm{GII}$

\begin{tabular}{lccc}
\hline \multicolumn{1}{c}{ Sex } & Gl & Gll & p-value \\
\hline Female & $26(55.3)$ & $17(53.1)$ & 0.848 \\
Male & $21(44.7)$ & $15(46.9)$ & \\
Total & $47(59.5)$ & $32(40.5)$ & \\
\hline
\end{tabular}

Values are presented as $\mathrm{n}(\%)$. Data were analyzed using Chisquare test. Gl: school-aged children with good academic performance, GIl: school-aged children with poor academic performance

Table 3 shows a comparison between the performance of the groups. There was a significant difference between test results in $\mathrm{S} \pi \mathrm{No}$ conditions between the two groups, while no differences were found both in SoNo conditions and the final result (MLD) (Table 3).

\section{Discussion}

Auditory integrity is essential for proper school learning and performance. The MLD test can be administered to detect lesions in the low brainstem, conductive hearing loss and cochlear lesions, depending on the extent of the pathology, and in cortical structures, including the corpus callosum [9]. The evaluation of binaural interaction in school-aged children is important for a variety of everyday listening activities, including localization and lateralization of auditory stimuli and detection of signals in noise backgrounds [9]. This research analyzed the performance of a pediatric sample to evaluate the binaural interaction mechanism with the MLD test. The test results were compared with those of school performance, contributing to a better understanding of the clinical administration of the MLD test in school-aged children.

Children from GI and GII were homogeneous in terms of sex, unlike other studies with school-aged children that found more male students in groups of risk for learning difficulty and/or CAPD [27,28]. In this study sample, the variables sex and age had no influence on the performance of both groups, in agreement with previous studies $[10,16,29,30]$. These data demonstrate that when the evaluated group has similar hearing thresholds and cognitive skills, such influence of sex is not observed. As the MLD test evaluates the lower brainstem region, it is expected that this structure has reached maturation. One study found that age effects are dependent on the masker bandwidth and signal duration [3]. Another study with children aged 4-6 showed that the age of four to five years could be considered a transitional period to reach adult performance level in the MLD test [4]. However, when analyzing the MLD components, another study found that adults performed better in the $\mathrm{S} \pi$ No condition compared to children, with high significance related to age, confirming the role of maturation in more complex analyses [3].

School difficulties have been associated with poor performance in different auditory skills [28]. The findings of this study reported no difference between GI and GII under SoNo conditions and in the final result (MLD). The literature suggests that attention-cognitive skills have little influence on binaural interaction. In the binaural hearing measurement, two conditions (SoNo and $\mathrm{S} \pi \mathrm{No}$ ) are compared in children, reducing the effect of cognitive and behavioral factors focused on the task [4]. Moreover, researchers have demonstrated that this phenomenon seems to be mediated in the CANS below the level of the auditory cortex. This is supported by patients with cortical pathology who consistently demonstrate MLDs comparable with those of normal listeners [13]. However, the findings of this study differ from other studies with specific clinical settings. A study analyzing children with Down syndrome (compared with children with typical development) showed a significant difference in the performance of both groups. Such findings suggest a delay in the maturation of this ability in children with Down syndrome, but this difference disappears when they become adults [5].

Our study showed a statistically significant difference between groups in the $\mathrm{S} \pi \mathrm{No}$ condition. Considering the mean value, this difference seems to be relevant. When the phase is the same, the threshold is high because stimuli and noise seem to be in the same source. But in the antiphasic condition, the stimuli are reversed relative to that of the noise, and the threshold is low, seeming to be in a different source [5]. So, the antiphasic condition is known to provide more auditory cues compared to the homophase condition, and a lower threshold for the antiphasic condition demonstrates an increase in detectability [14]. In this sense, children with good school performance may take advantage of the relatively favorable signalto-noise ratio. Therefore, another test that specifically assesses noise listening skills should complement the administration of MLD.

The mean performance on the MLD threshold of children in $\mathrm{GI}$ and GII was $13.66 \mathrm{~dB}$ and $13.25 \mathrm{~dB}$, respectively, unlike other Brazilian studies that found between $6.95 \mathrm{~dB}$ [18] and $7.65 \mathrm{~dB}[10]$ using the same version of the test. One of the reasons for this difference may be the small sample of these two cited studies -21 and 31 children, respectively. On the other hand, our findings were similar to those of studies with English and American children [5,29]. A study with 45 English children aged 6 to 11 reported a mean of $13.5 \mathrm{~dB}$ for 7-yearold children, and a study with 46 American children aged 3 to 12 reported a mean of $13.7 \mathrm{~dB}$. A study with 62 Australian children found a mean of $11.21 \mathrm{~dB}$ [16] and suggested that the MLD test is less culturally biased, in agreement with this 
study, but disagreeing with other Brazilian studies.

The MLD results in the good school performance group (GI), considering the mean and minus two SDs, showed a cut-off criterion of $9.3 \mathrm{~dB}$. This value has already been used in Brazilian clinical practice, based on international studies, and according to the SD. Although no relationship was found between school difficulties and MLD performance in this study, this test is recommended for the detection of brainstem diseases, particularly in the lower brainstem. However, it is less sensitive to assess specific listening difficulties in comorbidity with school difficulty.

The limitations of this study were the division of students (GI and GII) into groups and school difficulty classification based only on the perception of teachers and parents. However, the criterion of normal performance in the CAP battery test of children with good academic achievement (GI) was adopted.

In conclusion, in study 1 , the performance of school-aged children in the MLD test had a mean of $13.66 \mathrm{~dB}$. Considering the mean and minus two SDs, the cut-off criterion of this study was $9.3 \mathrm{~dB}$. The variables sex and age did not interfere with the MLD results. In study 2, school performance did not differ in the MLD results. Only in S $\pi$ No conditions did the group with school difficulties (GII) present inferior performance compared to children with good academic achievement (GI).

\section{Acknowledgments}

This research was funded by the São Paulo Research Foundation (FAPESP), grant (17/03317-6). We appreciate the collaboration of the school of Dona Castorina Cavalheiro staff, parents and children. The authors thank Espaço da Escrita - Research Rectory - School of Medical Sciences, the University of Campinas - for the language services provided.

\section{Conflicts of interest}

The authors have no financial conflicts of interest.

\section{Author Contributions}

Conceptualization: Nádia Giulian de Carvalho, Maria Isabel Ramos do Amaral, and Maria Francisca Colella dos Santos. Data curation: Nádia Giulian de Carvalho and Vinicius Zuffo de Barros. Formal analysis: Nádia Giulian de Carvalho, Maria Isabel Ramos do Amaral, and Maria Francisca Colella dos Santos. Funding acquisition: Nádia Giulian de Carvalho. Investigation: Nádia Giulian de Carvalho. Methodology: Nádia Giulian de Carvalho, Maria Isabel Ramos do Amaral, and Maria Francisca Colella dos Santos. Project administration: Nádia Giulian de Carvalho, Maria Isabel Ramos do Amaral, and Maria Francisca Colella dos Santos. Writing - original draft: Nádia Giulian de Carvalho and Vinicius Zuffo de Barros. Writingreview \& editing: Nádia Giulian de Carvalho, Maria Isabel Ramos do Amaral, and Maria Francisca Colella dos Santos. Approval of final manuscript: All authors.

\section{ORCID iDs}

Nádia Giulian de Carvalho

https://orcid.org/0000-0003-2475-0095

Maria Isabel Ramos do Amaral https://orcid.org/0000-0002-6909-3597

Vinicius Zuffo de Barros https://orcid.org/0000-0002-6600-9388

Maria Francisca Colella dos Santos https://orcid.org/0000-0002-7456-9502

\section{REFERENCES}

1) American Speech-Language-Hearing Association (ASHA). (Central) auditory processing disorders [Internet]. ASHA; 2005 [cited 2019 Apr 9]. Available from: URL: https://www.asha.org/policy/ tr2005-00043/.

2) Musiek FE, Chermak GD, Bamiou DE, Shinn J. CAPD: the most common 'hidden hearing loss' central auditory processing disorder--and not cochlear synaptopathy--is the most likely source of difficulty understanding speech in noise (despite normal audiograms). The ASHA Leader 2018;23:6-9.

3) Hall JW, Buss E, Grose JH, Dev MB. Developmental effects in the masking-level difference. J Speech Lang Hear Res 2004;47:13-20.

4) Van Deun L, van Wieringen A, Van den Bogaert T, Scherf F, Offeciers FE, Van de Heyning PH, et al. Sound localization, sound lateralization, and binaural masking level differences in young children with normal hearing. Ear Hear 2009;30:178-90.

5) Porter HL, Grantham DW, Ashmead DH, Tharpe AM. Binaural masking release in children with Down syndrome. Ear Hear 2014; 35:e134-42.

6) McCullagh J, Bamiou DE. Measures of binaural interaction. In: Handbook of Central Auditory Processing Disorder: Auditory Neuroscience and Diagnosis (eds. Musiek FE, Chermak GD), 2nd ed. San Diego: Plural Publishing;2014. p.435-69.

7) Hughes LE, Rowe JB, Ghosh BC, Carlyon RP, Plack CJ, Gockel HE. The binaural masking level difference: cortical correlates persist despite severe brain stem atrophy in progressive supranuclear palsy. J Neurophysiol 2014;112:3086-94.

8) Cameron S, Dillon H. Remediation of spatial processing issues in CAPD. In: Handbook of Central Auditory Processing Disorder: Comprehensive Intervention (eds. Chermak GD, Musiek FE), 2nd ed. San Diego: Plural Publishing;2014. p.201-24.

9) Bellis TJ. Assessment and management of central auditory processing disorders in the educational setting. From science to practice. 2nd ed. San Diego, USA: Plural Publishing;2013. p.51-102.

10) Martins QP, Faccin VA, Brückmann M, Gil D, Garcia MV. Masking level difference in schoolchildren: environmental analysis. Codas 2018;30:e20170048.

11) Sousa FMAA. Learning disorders and difficulties: a perspective of interface between health and education. In: Disorders and Learning Difficulties: Better Understanding Students with Educational Needs Special (eds. Sampaio S, de Freitas IB), 2nd ed. Rio de Janeiro: Wak Editora;2014. p.17-36.

12) Hirsh IJ, Webster FA. Some determinants of interaural phase effects. J Acoust Soc Am 1949;21:496-501.

13) Frota S. Auditory processing assessment: behavioral tests. In: Treaty of Audiology (eds. Bevilacqua MC, Martinez MAN, Balen AS, Pupo AC, Reis ACMB, Frota S). São Paulo: Santos;2011. p.293-313.

14) Brown M, Musiek F. Pathways: the fundamentals of masking level differences for assessing auditory function. Hear J 2013;66:16-7.

15) Branco-Barreiro FCA, Momensohn-Santos TM. Evaluation and intervention speech therapy of auditory processing disorder (central). In: Speech Therapy Treaty (eds. Fernandes FDM, Mendes BCA, Navas ALGP), 2nd ed. São Paulo: Roca;2009. p.232-8. 
16) Aithal V, Yonovitz AL, Aithal S, Dold N. Tonal masking level difference in children. Aust New Zeal J Audiol 2006;28:11-7.

17) Mendes SDC, Branco-Barreiro FCA, Frota S. Masking level difference: reference values in adults. Audiol Commun Res 2017;22:e1746.

18) Gicov RA, Tordin GC, Santos TMM, Branco-Barreiro FCA. Masking level difference in seven-to-eight-year-old children. RECES 2015;7:17-20.

19) Northern JL, Downs MP. Childhood hearing. 5th ed. Rio de Janeiro, Brazil: Guanabara Koogan;2005. p.129-67.

20) Jerger J, Speaks C, Trammell JL. A new approach to speech audiometry. J Speech Hear Disord 1968;33:318-28.

21) Jerger S, Jerger J. Hearing disorders: an assessment manual clinic. 1st ed. São Paulo, Brazil: Atheneu;1989. p.102.

22) Pereira LD, Schochat E. Central auditory processing: evaluation manual. 1st ed. São Paulo, Brazil: Lovise;1997. p.49-60.

23) Keith RW. Random gap detection test. St. Louis, USA: Auditec; 2000

24) Auditec. Evaluation manual of pitch pattern sequence and duration pattern sequence. St. Louis, USA: Auditec;1997.
25) Musiek FE. Frequency (pitch) and duration pattern tests. J Am Acad Audiol 1994;5:265-8.

26) Wilson RH, Moncrieff DW, Townsend EA, Pillion AL. Development of a $500-\mathrm{Hz}$ masking-level difference protocol for clinic use. J Am Acad Audiol 2003;14:1-8.

27) Nogueira JCR, Mendonça MC. Assessment of hearing in a municipal public school student population. Braz J Otorhinolaryngol 2011;77:716-20

28) de Carvalho NG, Novelli CVL, Colella-Santos MF. Evaluation of speech in noise abilities in school children. Int J Pediatr Otorhinolaryngol 2017;99:66-72.

29) Moore DR, Cowan JA, Riley A, Edmondson-Jones AM, Ferguson MA. Development of auditory processing in 6- to 11-yr-old children. Ear Hear 2011;32:269-85.

30) Bartz DW, Laux CN, Peruch CV, Ferreira MIDC, Machado MS, Ribas LP. Relationship between masking level difference test and acoustic reflex findings in children with phonological disorder. Rev CEFAC 2015;17:1499-508. 